\title{
Colorectal Surgery in Elderly Patients
}

\author{
Byung Chun Kim \\ Department of Surgery, Hallym University Kangnam Sacred Heart Hospital, Hallym University College of Medicine, Seoul, Korea
}

\section{See Article on Page 139-143}

With the increase in life expectancy comes an increase in the number of elderly people with colorectal diseases; accordingly, the number of elderly people needing colorectal surgery has increased. Furthermore, the incidence of colorectal carcinomas increases with advancing age. Thus, age is a major risk factor for the development of colorectal cancer [1], and advanced age is considered an important and independent risk factor for postoperative morbidity and mortality. Elderly patients are often considered high-risk patients due to their having significant comorbidity, which results in increased postoperative morbidity and mortality.

The incidence of pulmonary and cardiovascular complications increases significantly with age. Moreover, the main causes of postoperative morbidity in elderly patients are pulmonary and cardiovascular complications, together with thromboembolisms [2]. Especially, emergent colorectal surgery is associated with appreciably elevated morbidity and mortality rates. However, no differences in intraoperative complications between old and young patients have been documented, and surgery involving elderly patients is not necessarily associated with an increase in surgery-related complications. The impact of age on postoperative outcome after major colorectal surgery remains controversial.

The problem is that the term 'elderly' is a very subjective term, with the cutoff between young and old being quite subjective. The World Health Organization defined 'elderly' as being older than 65 years of age. In spite of that, some authors have defined the threshold for old age as 65 years [3] and as greater than 70 years or 75 years $[4,5]$, or even 80 years $[6,7]$. Age over 80 has been shown to be a possible risk factor for postoperative morbidity after a laparoscopic resection of colorectal cancer [8]. In addition,

\section{Correspondence to: Byung Chun Kim, M.D.}

Department of Surgery, Kangnam Sacred Heart Hospital, Hallym University

College of Medicine, 1 Singil-ro, Yeongdeungpo-gu, Seoul 07441, Korea

Tel: +82-2-829-5130, Fax: +82-2-849-4469

E-mail: bckimgs@hallym.or.kr

(C) 2016 The Korean Society of Coloproctology

This is an open-access article distributed under the terms of the Creative Commons Attribution NonCommercial License (http://creativecommons.org/licenses/by-nc/4.0) which permits unrestricted noncommercial use, distribution, and reproduction in any medium, provided the original work is properly cited. in one study, cutoff ages of 70 and 75 years were not significant risk factors for compromised postoperative morbidity [9]. On the other hand, many studies have adopted an age greater than 80 as the cutoff value for defining an 'elderly' patient. The results of those studies demonstrated age over 80 to be an independent risk factor for worse short-term outcomes after colorectal surgery. Patients over 80 years of age usually have a high risk profile, which might influence the postoperative outcome.

In this study, the authors evaluated the impact of age on shortterm outcomes after colorectal surgery in patients 80 years of age and older in comparison to patients younger than 80 . However, this study has some limitations. It was a retrospective review, and the number of patients was not very high. Also, the study used the Charson Comorbidity Index, which has some limitations. The authors said that advancing age was neither a contraindication to colorectal surgery nor a bad predictive factor for the outcome after such surgery. Rather, pre-existing comorbidity and the urgent nature of the procedure were more important predictors of outcomes of colorectal surgeries performed on elderly patients [10].

Colorectal surgery in elderly patients can be performed safely because of improvements in anesthesia, perioperative care, and surgical technique, especially laparoscopic surgery. Age alone should not be considered a contraindication for colorectal surgery in elderly patients. However, extra care must be taken with elderly patients undergoing emergent colorectal surgery.

\section{CONFLICT OF INTEREST}

No potential conflict of interest relevant to this article was reported.

\section{REFERENCES}

1. de Rijke JM, Schouten LJ, Hillen HF, Kiemeney LA, Coebergh JW, van den Brandt PA. Cancer in the very elderly Dutch population. Cancer 2000;89:1121-33.

2. Colorectal Cancer Collaborative Group. Surgery for colorectal cancer in elderly patients: a systematic review. Lancet 2000;356: 968-74.

3. Paksoy M, Ipek T, Colak T, Cebeci H. Influence of age on prognosis and management of patients with colorectal carcinoma. Eur 
J Surg 1999;165:55-9.

4. Arenal JJ, Benito C, Concejo MP, Ortega E. Colorectal resection and primary anastomosis in patients aged 70 and older: prospective study. Eur J Surg 1999;165:593-7.

5. Makela JT, Kiviniemi H, Laitinen S. Survival after operations for colorectal cancer in patients aged 75 years or over. Eur J Surg 2000; 166:473-9.

6. Marusch F, Koch A, Schmidt U, Zippel R, Gastmeier J, Ludwig K, et al. Impact of age on the short-term postoperative outcome of patients undergoing surgery for colorectal carcinoma. Int J Colorectal Dis 2002;17:177-84.

7. Spivak H, Maele DV, Friedman I, Nussbaum M. Colorectal sur- gery in octogenarians. J Am Coll Surg 1996;183:46-50.

8. Kang T, Kim HO, Kim H, Chun HK, Han WK, Jung KU. Age over 80 is a possible risk factor for postoperative morbidity after a laparoscopic resection of colorectal cancer. Ann Coloproctol 2015; 31:228-34.

9. Bircan HY, Koc B, Ozcelik U, Adas G, Karahan S, Demirag A. Are there any differences between age groups regarding colorectal surgery in elderly patients? BMC Surg 2014;14:44.

10. Shalaby M, Di Lorenzo N, Franceschilli L, Perrone F, Angelucci GP, Quareisma S, et al. Outcome of colorectal surgery in elderly populations. Ann Coloproctol 2016;32:139-43. 